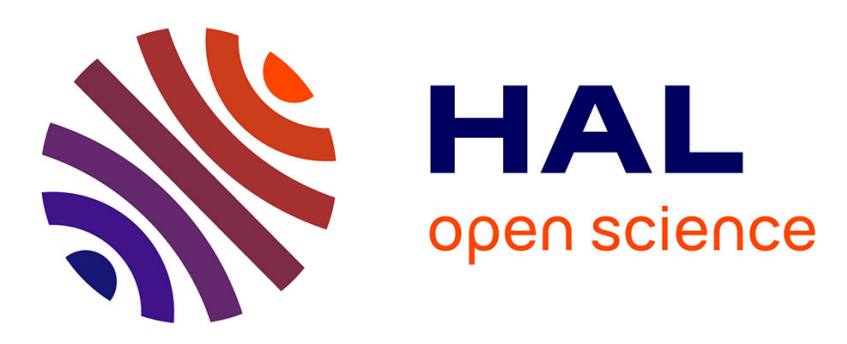

\title{
Controlled fabrication of patterned lateral porous alumina membranes
}

Manoraham Gowtham, Laurent Eude, Costel Sorin Cojocaru, Berndt

Marquardt, Hee Jeen Jeong, Pierre Legagneux, Kim K Song, Didier Pribat

\section{- To cite this version:}

Manoraham Gowtham, Laurent Eude, Costel Sorin Cojocaru, Berndt Marquardt, Hee Jeen Jeong, et al. Controlled fabrication of patterned lateral porous alumina membranes. Nanotechnology, 2008, 19, pp.035303. 10.1088/0957-4484/19/03/035303 . hal-00795369

\section{HAL Id: hal-00795369 \\ https://hal.science/hal-00795369}

Submitted on 28 Feb 2013

HAL is a multi-disciplinary open access archive for the deposit and dissemination of scientific research documents, whether they are published or not. The documents may come from teaching and research institutions in France or abroad, or from public or private research centers.
L'archive ouverte pluridisciplinaire HAL, est destinée au dépôt et à la diffusion de documents scientifiques de niveau recherche, publiés ou non, émanant des établissements d'enseignement et de recherche français ou étrangers, des laboratoires publics ou privés. 


\title{
Controlled fabrication of patterned lateral porous alumina membranes
}

\author{
M Gowtham ${ }^{1}$, L Eude ${ }^{1}$, C S Cojocaru ${ }^{1}$, B Marquardt ${ }^{1}$, H J Jeong ${ }^{1}$, \\ $P$ Legagneux ${ }^{2}$, K K Song ${ }^{3}$ and $D$ Pribat $^{1}$ \\ ${ }^{1}$ Laboratoire de Physique des Interfaces et des Couches Minces, Ecole Polytechnique, \\ 91128, Palaiseau, France \\ 2 Thales Research and Technology, 91128 Palaiseau, France \\ ${ }^{3}$ Samsung Electronics, Giheung-Gu, Yongin-City, Gyeonggi-Do, 446-711, Korea
}

\begin{abstract}
Confined lateral alumina templates are fabricated with different pore sizes by changing the acid electrolyte and the anodization voltage. The control of the number of pore rows down to one dimension is also achieved, by controlling the thickness of the starting aluminum film as well as the anodization voltage. We observe that the mechanism of pore formation in the lateral regime is very similar to that in the classical vertical situation.
\end{abstract}

\section{Introduction}

Ordered nanoporous materials have attracted increasing attention in recent years due to their possible utilization as templates for the organization of nanosize structures [1, 2]. One approach to the fabrication of such templates has been to use anodic porous alumina, which is prepared by the anodic oxidation of aluminum in an acidic electrolyte. Anodic porous alumina is one of the typical self-organized fine structures with nanohole arrays, which has been studied in detail in various electrolytes over the last five decades [3, 4] and over. Selforganized pore growth, leading to a densely packed hexagonal pore structure of anodic porous nanochannel material has been reported for certain sets of parameters [5]. Such structures can be used for the organization of nanotubes and nanowires: they provide parallelism and above all, end-to-end registration. For instance, vertically aligned carbon nanotubes (CNTs) arrays have been fabricated by chemical vapor deposition using porous anodic alumina (PAA) as templates [6, 7]. Recently, the growth of SWNTs inside PAA templates in vertical configuration has been demonstrated by Fisher et al [8]. Silicon nanowires with well-controlled diameters ranging from 100 to $340 \mathrm{~nm}$ were also grown in PAA membranes [9]. In the usual situation, the pore array and hence the array of template-grown nano objects are perpendicular to the surface of the substrate, which complicates (from a topographic point of view) the organization of electrical contacts, as far as three terminal devices are concerned. In integrated circuit fabrication processes, a planar type configuration is preferred for transistor-type devices. Masuda et al [10] attempted the fabrication of lateral alumina templates on glass. In their process they used glass substrates which are not compatible with integrated device fabrication. The first process for lateral anodic pore synthesis, compatible with CMOS fabrication, was reported by our group in 2005 [11], soon followed by Chen et al [12]. In particular, Chen et al showed a onedimensional row of nanopores. Here we present a systematic study of the synthesis of lateral templates with various pore sizes, varying from 5 to $100 \mathrm{~nm}$ that can be used to grow single wall carbon nanotubes (SWNTs) and semiconductor nanowires (NWs). On the other hand, we have already shown the potential advantages (particularly in terms of mask count) of growing silicon nanowires inside lateral PAA templates for active matrix-type applications such as displays or $\mathrm{x}$-ray image sensors [13, 14].

\section{Experimental details}

Figure 1 shows the general scheme that we use to synthesize PAA membranes having their pore direction parallel to the surface of the substrate.

For the experiments presented here, we have deposited aluminum thin films by DC magnetron sputtering on silicon 

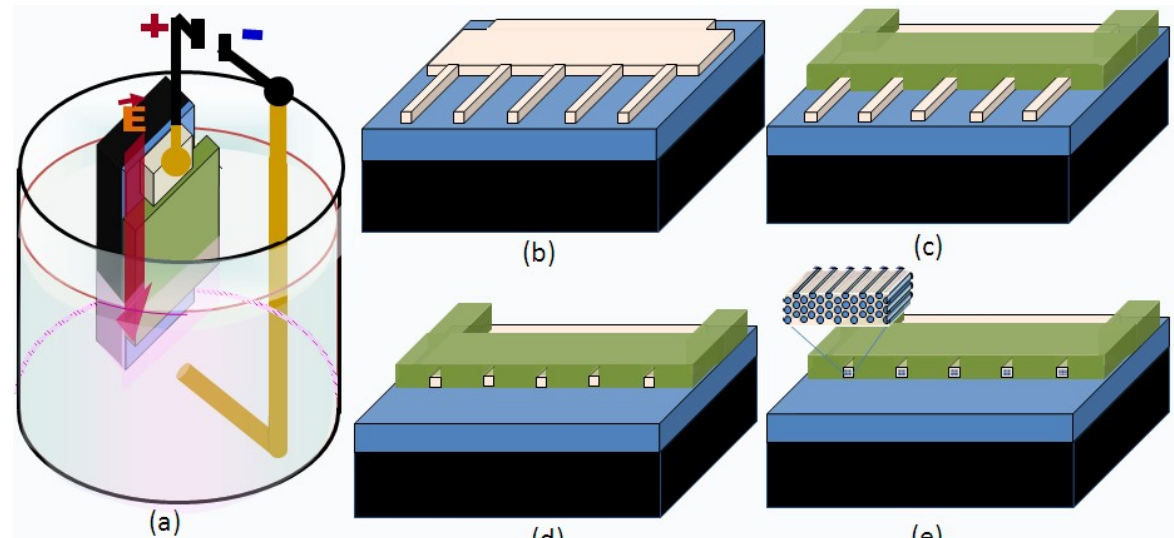

(b)

(c)

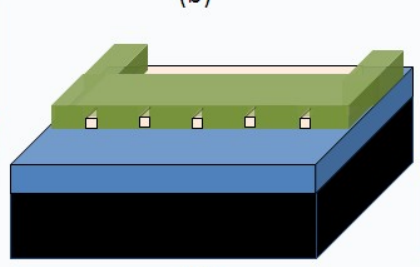

(d)

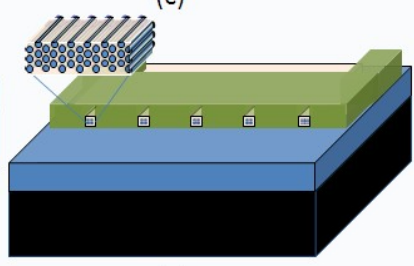

(e)

Figure 1. (a) Anodization setup-individual Al stripes (connected at the periphery) are partially immersed into the electrochemical bath for anodic oxidation. Because of the engineered structure with the insulating capping layer, the anodic oxidation current is forced to flow parallel to the surface of the substrate. Hence the porous structure is also forced to develop parallel to the surface of the substrate. Process steps for the fabrication are shown from (b) to (e). (b) $500 \mathrm{~nm}$ thick thermal oxide on the Si substrate and the patterned aluminum film. (c) After deposition of silicon oxide by plasma enhanced chemical vapor deposition on aluminum stripes and etching. (d) After modified electro polishing. (e) Lateral pores (see the magnification in the inset) after anodization.

Table 1. Summary of the variations of pore diameter versus the anodization voltage in different acid electrolytes.

\begin{tabular}{lllccccccc}
\hline & & \multicolumn{3}{c}{ First anodization } & \multicolumn{5}{c}{ Second anodization } \\
\cline { 3 - 6 } Sample & Acid & $T\left({ }^{\circ} \mathrm{C}\right)$ & $V(\mathrm{~V})$ & $t(\mathrm{~s})$ & Oxide removal $(\mathrm{s})$ & $T\left({ }^{\circ} \mathrm{C}\right)$ & $V(\mathrm{~V})$ & $t(\mathrm{~s})$ & Pore diameter, $\mathrm{O}^{\mathrm{a}}(\mathrm{nm})$ \\
\hline $\mathrm{a}$ & Sulphuric & 0 & 10 & 300 & 300 & 0 & 10 & 300 & 11 \\
$\mathrm{~b}$ & Oxalic & 0 & 20 & 300 & 300 & 0 & 20 & 300 & 16 \\
$\mathrm{c}$ & Oxalic & 0 & 25 & 300 & 300 & 0 & 25 & 300 & 22 \\
$\mathrm{~d}$ & Oxalic & 0 & 40 & 300 & 300 & 0 & 40 & 300 & 36 \\
$\mathrm{e}$ & Oxalic & 0 & 50 & 3000 & 0 & 0 & 0 & 0 & 62 \\
$\mathrm{f}$ & Phosphoric & 0 & 100 & 3000 & 0 & 0 & 0 & 0 & 87 \\
\hline
\end{tabular}

a, o-errors will be in the range of $<5 \mathrm{~nm}$ and the decimal values are rounded off.

wafers covered with thermal oxide. The Al thickness ranged from $50 \mathrm{~nm}$ to $2000 \mathrm{~nm}$. The Al films were subsequently etched in line stripes with different widths, ranging from 1 to $50 \mu \mathrm{m}$ and separated by equal spacing. There are five consecutive stripes with the same width (figure 1(b)) followed by another set in ascending order (i.e. 1, 2, 5, 10, 20, $50 \mu \mathrm{m})$. After Al etching, a $500 \mathrm{~nm}$ thick insulating layer of $\mathrm{SiO}_{2}$ was deposited on the aluminum patterned wafer by rf-plasma enhanced CVD, thus covering the stripes. This $\mathrm{SiO}_{2}$ layer was then patterned and reactive ion etched (RIE) using a second mask consisting of two openings, one in front and one at the back. The opening at the front side is perpendicular to the first network of $\mathrm{Al}$ stripes and the opening at the back side provides an electrical contact to the $\mathrm{Al}$ thin film for electro polishing and anodic oxidation (figure 1(c)). This process step left the Al locally exposed on both sides. Prior to performing anodic oxidation, the $\mathrm{SiO}_{2}$-capped $\mathrm{Al}$ stripes prepared as shown in figure 1(d) by partially immersed into an electrochemical bath of perchloric acid in ethanol (25 vol\%) and they were electro polished for 2-10 s at 2$5 \mathrm{~V}$ constant voltage at $0{ }^{\circ} \mathrm{C}\left( \pm 0.5^{\circ} \mathrm{C}\right)$. The anodic oxidation experiments were carried out with different acidic solutions (say 0.3 M sulfuric, $0.3 \mathrm{M}$ oxalic and $0.1 \mathrm{M}$ phosphoric acid) and different voltages, as summarized in table 1 . During the anodization the acid bath was continuously magnetically stirred and kept at constant temperature. The anodic voltage was applied between the exposed $\mathrm{Al}$ peripheral part (the latter being maintained out of the electrochemical bath) and an $\mathrm{Au}$ counter-electrode immersed in the electrochemical bath (see figure 1(a)). Depending on the desired pore diameter different voltage values have been used, varying between 10 and $100 \mathrm{~V}$. All anodic oxidation experiments have been carried out at constant applied voltage while the anodic current could flow freely. To increase the ordering quality of the porous structures, a two-step process was performed in most cases [5]. The first oxidation is carried out for typically $5 \mathrm{~min}$, followed by oxide dissolution in a mixture of chromic acid (1.7 wt\%) and phosphoric acid (6 wt\%) for $5 \mathrm{~min}$ at $60{ }^{\circ} \mathrm{C}$. A second oxidation is then performed under the same conditions as the first one. After anodization, with of lateral pore structure the enlarged skeleton shown in the inset in figure 1(e). The morphology of the samples after anodic oxidation was investigated with a Hitachi S4800 FEG highresolution scanning electron microscope (SEM), working at $1 \mathrm{kV}$. For the thin aluminum samples the capping $\mathrm{SiO}_{2}$ was removed prior to observation by a standard RIE process $\left(\mathrm{CF}_{4}\right.$ and $\mathrm{CHF}_{3}$ 1:5 mixture), thus exposing the $\mathrm{Al}$ stripes and the porous alumina membrane. To ensure a better observation of the lateral pore structure we also used focused ion beam etching (FIB) of the membranes (Zeiss CrossBeam 1560). For 


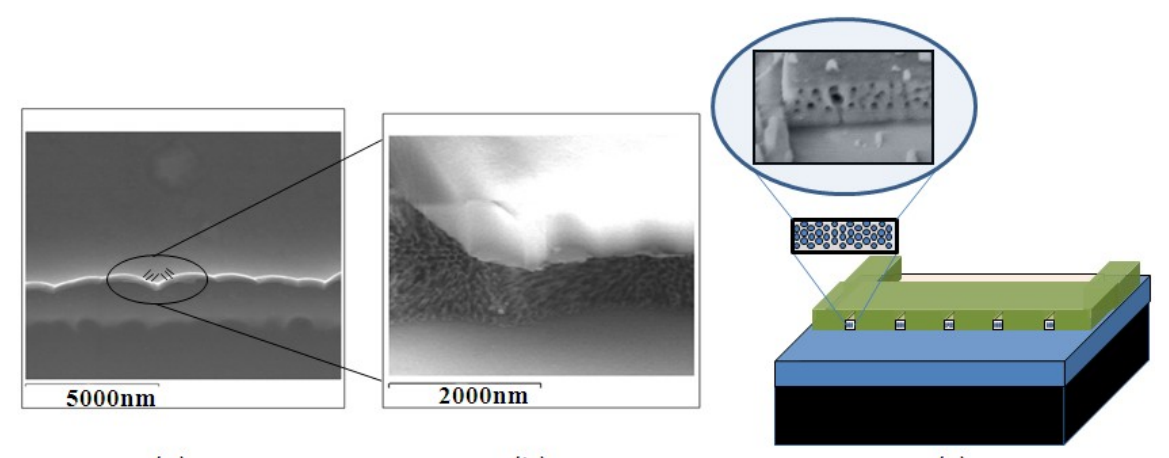

(a)

(b)

(c)

Figure 2. (a) Aspect of the chemically etched $\mathrm{Al}$ etch front after removal of the top $\mathrm{SiO}_{2}$ cap, the lines represent the electric field direction upon anodization. (b) The anodic membrane replicates the meandering etch front of the starting Al film inducing some 'mixing' of the pores. (c) shows the anodic membrane after our modified electro polishing process (see text for details).

the pore diameter calculation from the SEM images we used the 'Image J' program (public domain image processing and analysis program developed at the Research Services Branch (RSB) of the National Institutes of Health (NIH), USA). For the rectangular portion of about 1-2 rows in the center of each image we made a plot profile (gray value versus distance along the image). This plot consists of peaks and troughs; the width of the trough portion gives the pore diameter. The pore diameter value and interpore distance which are shown in the present work are the average values calculated from these plot profiles.

\section{Results and discussion}

After the entire process the four inch wafer is diced into separate cells. Before anodization a short electro polishing step is performed at a temperature of $0{ }^{\circ} \mathrm{C}$ and a precise control of the etched length is achieved by diluting the solution with ethanol. To obtain well-organized pore arrays, parallel to the surface of the substrate and also parallel between each other, we have found that it was necessary to start the anodic oxidation (anodization) with a sharp and straight edge for the $\mathrm{Al}$ film. Moreover, the Al edge also needs to be perpendicular to the substrate and not tapered. All this is accomplished by our modified electro polish step before starting the anodization. Note that the same result could be obtained by a proper reactive ion etch (RIE) processing of the Al thin film. With the above requirements on the geometrical aspect of the starting $\mathrm{Al}$ film and the direct consequence of the field-assisted mechanism of pore formation, the pores will be perpendicular to the local equipotential, i.e., the very $\mathrm{Al}$ wall in our case [15]. When the Al film is simply chemically etched, a meandering edge is observed, leading to interpenetration of the pore structure after anodization, as explained on figure 2 below. This situation would obviously be detrimental for device-oriented nanotubes or nanowires organization.

At this point, we emphasize that different pore diameters are needed depending on whether CNTs or semiconductor NWs are of concern. In other words, pore diameters in the 3-nm range are interesting for templating CNTs, whereas for semiconductor NWs, the range of diameters can spread between, say, 10 and $100 \mathrm{~nm}$. Typically, the pore diameter $>Z$, and the interpore distance, $D_{\text {int }}$, are proportional to the anodization voltage $(V)$. In other words, $>Z=k_{1} V$ and $D_{\text {int }}=k_{2} V$, where $k_{1} \sim 1.29 \mathrm{~nm} \mathrm{~V}^{-1}$ and $k_{2} \sim$ $2.5 \mathrm{~nm} \mathrm{~V}^{-1}$ [16]. This relationship probably varies somewhat with anodizing conditions (temperature in particular), although it was confirmed approximately in experiments [4]. Under appropriate anodic oxidation conditions, very regular selfordered, honeycomb-like hexagonal arrays with a circular pore at the center of each hexagonal cell can be obtained [5]. This self-ordering regime of pore growth seems to originate from an equilibrium where the mechanical stress at the $\mathrm{Al}_{2} \mathrm{O}_{3} / \mathrm{Al}$ interface (due to volume change upon oxidation) is partially compensated by a $\sim 10 \%$ porosity of the anodic oxide $[17,18]$. Generally speaking, the ordering quality of the pores depends on the anodic voltage and every acid has a specific voltage range where the ordering is maximum $[5,18]$. For example in the case of oxalic acid, an anodic voltage around $40 \mathrm{~V}$ seems to be preferable in order to obtain highly ordered structures. The same phenomena occur for sulfuric and phosphoric acids, but around 20 and $160 \mathrm{~V}$ respectively. On the other hand, the type and the concentration of the electrolyte for a given voltage have to be selected properly in order to obtain pores with given diameters. In other words, the choice of the type of electrolyte is restricted for ordered arrays. Usually, the anodization of aluminum is carried out in sulfuric acid at low voltage ranges (5-30 V), oxalic acid is used for medium voltage ranges (30$120 \mathrm{~V}$ ) and phosphoric acid for high voltage ranges (80$200 \mathrm{~V}$ ). These restrictions are due to the conductivity and $\mathrm{pH}$ value of the various electrolytes. For example, if aluminum is anodized in sulfuric acid at a high voltage (note that sulfuric acid has a very high conductivity), breakdown of the oxide layer takes place. In addition, the $\mathrm{pH}$-value of the electrolyte determines the diameter of the pores or more precisely the size of the hexagonal cell around one pore. The lower the $\mathrm{pH}$ value, the lower the voltage threshold for field-enhanced dissolution at the pore tip. Therefore, since the pore diameter is directly proportional to the anodization voltage, small pore diameters are obtained in the lowest $\mathrm{pH}$ value i.e., in the strongest acid (sulfuric acid) and large pore diameters are formed by using phosphoric acid. Interestingly, Nielsch et al have shown 


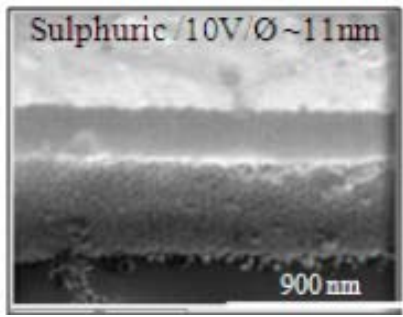

(a)

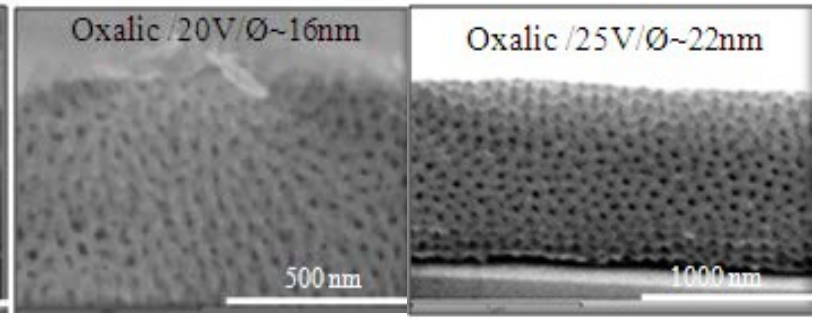

(b) (c)

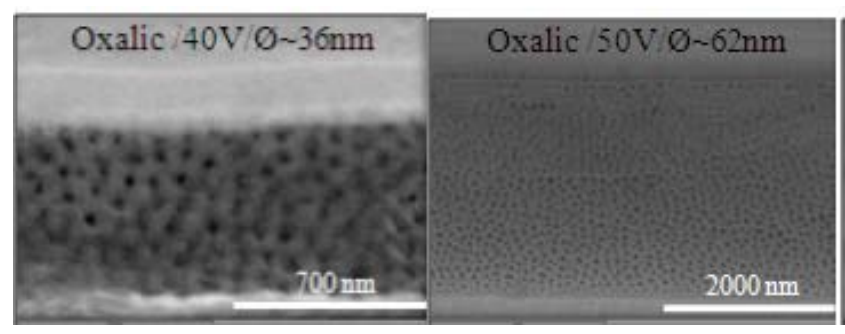

(d)

(e)

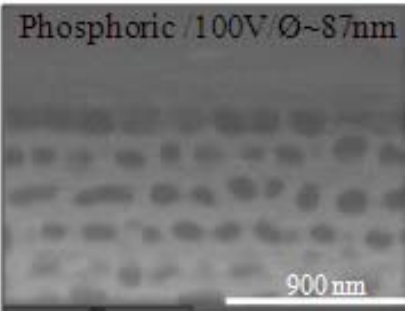

(f)

Figure 3. Scanning electron microscope images of the lateral templates showing different pore diameters obtained by changing the anodization voltage and the acid electrolyte (the top part of each picture gives the type of acid/anodization voltage/approximate pore diameter).

Table 2. Porosity calculation for the samples shown in figure 3.

\begin{tabular}{lclccc}
\hline Sample & $\begin{array}{l}V \\
(\mathrm{~V})\end{array}$ & $\begin{array}{l}\mathrm{O}^{\mathrm{a}} \\
(\mathrm{nm})\end{array}$ & $\begin{array}{l}r=, 0 / 2 \\
(\mathrm{~nm})\end{array}$ & $\begin{array}{l}D_{\text {int }} \\
(\mathrm{nm})\end{array}$ & $P(\%)$ \\
\hline $\mathrm{a}$ & 10 & 11 & 5.5 & 44 & 6 \\
$\mathrm{~b}$ & 20 & 16 & 8 & 54 & 8 \\
$\mathrm{c}$ & 25 & 22 & 11 & 106 & 4 \\
$\mathrm{~d}$ & 40 & 36 & 18 & 101 & 11 \\
$\mathrm{e}$ & 50 & 62 & 31 & 98 & 36 \\
$\mathrm{f}$ & 100 & 87 & 43.5 & 198 & 17
\end{tabular}

${ }^{a}$ Errors will be in the range of $<5 \mathrm{~nm}$ and the decimal values are rounded off.

that, whatever the pore diameter and interpore distance, selfordering occurred as long as the porosity of the anodic alumina remained around 10\% [18].

Table 1 and figure 3 shows the variation of the pore diameter with respect to the anodization voltage in different type of electrolytes. Following Nielsch et al [18], we calculated the porosity of the hexagonal structure by the following equation.

$$
P=\frac{2 \pi}{\frac{1}{3}} \frac{r^{\mathbf{I}_{2}}}{D_{\mathrm{int}}}
$$

where $r$ is the radius of the pore and $D_{\text {int }}$ is the interpore distance.

Since $r / D_{\text {int }}$ is constant in the self-ordering regime [18], we find porosity around $9 \%$ for the $40 \mathrm{~V}$ oxalic acid sample which is obviously the best organized one (see figure 3). For the other samples the porosity varies significantly from $5 \%$ to $40 \%$ (shown in table 2), due to the anodization voltages which do not correspond to the self-ordered regime. So, whether the anodization is performed in a vertical or lateral way does not seem to change the $10 \%$ porosity rule [18].
We started with low anodic voltages to get pores exhibiting

therefore used sulfuric acid with a concentration of $0.5 \mathrm{M}$ and a bath temperature of $0{ }^{\circ} \mathrm{C}$. But the degree of self-organization of the structure is less when compared to the observation of the pore structure made with oxalic acid (figure 3), which is probably due to the higher oxide growth rate and lower Al dissolution rate. As also quoted above, self-organization increases when we increase the voltage towards the selfordered regime. This phenomenon is shown on figures 3(b)(d) for the case corresponding to the anodization in oxalic acid, where the anodization voltage rises from 20 to $40 \mathrm{~V}$. Previous studies [16, 19] have shown that ordered pore arrangement occurs in a stable anodic state, i.e., stable voltage and current. During anodization at $100 \mathrm{~V}$ (in $\mathrm{H}_{3} \mathrm{PO}_{4}$ ) the anodization current is not stable (not shown here) which leads to the disordered pore arrangement. Chemical pore widening is done for the samples shown in figures 3(e) and (f) just after the first anodization instead of second anodization.

In figure 4 we show the comparison of our vertical and lateral templates results. It seems there is no significant difference between them. And also these results are comparable with the general trend. Here we have taken Nielsch et al [18] as reference. The sudden jump in the pore diameter for the lateral template (blue triangle) for $50 \mathrm{~V}$ is due to the chemical pore widening explained before.

Table 3 and figure 5 show that the size of the arrays can be controlled by controlling the thickness of the aluminum layer and the cell size obtained at each applied voltage. So we fixed the acid as well as the temperature and we changed the $\mathrm{Al}$ thickness from $2 \mu \mathrm{m}$ to $50 \mathrm{~nm}$, while imposing the appropriate voltage for each anodization. With the $2 \mu \mathrm{m}$ aluminum thickness, we obtained about 30 lines of pores by controlling the anodization voltage at $20 \mathrm{~V}$. The number of lines in the 


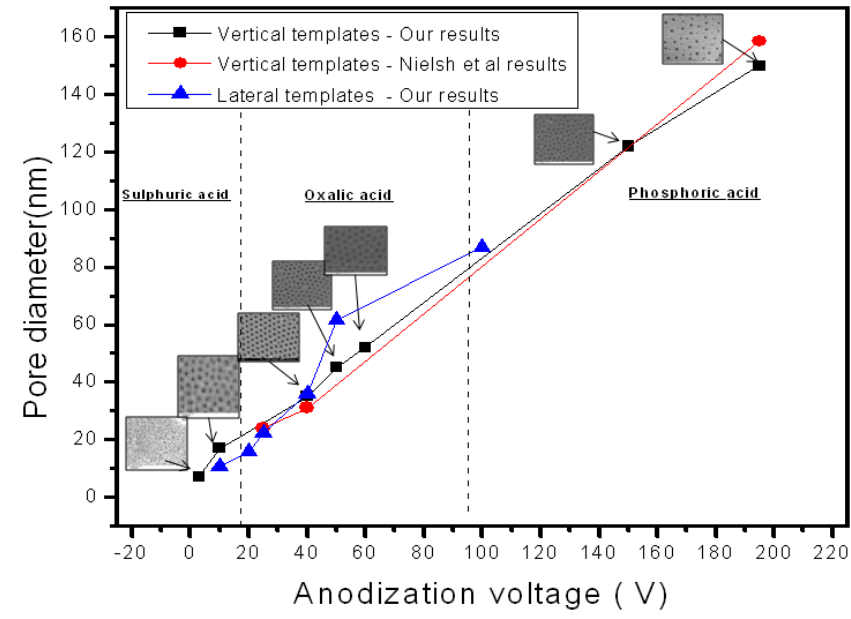

Figure 4. Pore diameters versus anodization voltage trend for our vertical templates (square), the lateral templates (triangle) compared with the Nielsh et al results (circles).

pore array can be decreased by keeping the thickness constant and changing the voltage. For example, when the aluminum thickness is about $1 \mu \mathrm{m}$, the size of pore arrays can be varied from 15 to 10 lines, just by changing the anodization voltages from 25 to $40 \mathrm{~V}$ (figures 5(h) and (i)). For a low Al thickness, say about $200 \mathrm{~nm}$ and below, it is difficult to see the pores after the second anodization, since the alumina wall is far away from the $\mathrm{SiO}_{2}$ edge, following dissolution of the anodic oxide after the first anodization step. Hence we used RIE to etch the $\mathrm{SiO}_{2}$ cap and were able to observe the pore arrays (notice some of the remains of the $\mathrm{SiO}_{2}$ etching in figures 5(j)-(l)). The thickness of the aluminum used for the one-dimensional array (figure $5(\mathrm{l})$ ) is about $50 \mathrm{~nm}$, and the pore diameter is about $20 \mathrm{~nm}$. This is the smallest one-dimensional alumina pore array reported. Actually, starting with a $50 \mathrm{~nm}$ Al thickness
Table 3. Variation of the number of pore rows by changing the aluminum thickness and the anodization voltages (see the corresponding pictures on figure 5).

\begin{tabular}{|c|c|c|c|c|}
\hline Sample & Acid & $\begin{array}{l}\text { Anodization } \\
\text { voltage } \\
\text { (V) }\end{array}$ & $\begin{array}{l}\text { Aluminum } \\
\text { thickness } \\
(\mathrm{nm})\end{array}$ & $\begin{array}{l}\text { Number of } \\
\text { rows }\end{array}$ \\
\hline g & Oxalic & 20 & $\sim 2000$ & $\sim 30$ \\
\hline h & Oxalic & 40 & $\sim 1000$ & $\sim 10$ \\
\hline $\mathrm{i}$ & Oxalic & 25 & $\sim 1000$ & $\sim 15$ \\
\hline j & Oxalic & 40 & $\sim 250$ & $\sim 4$ \\
\hline $\mathrm{k}$ & Oxalic & 40 & $\sim 200$ & $\sim 3$ \\
\hline 1 & Oxalic & 20 & $\sim 50$ & $\sim 1$ \\
\hline
\end{tabular}

should lead to 2 rows of $20 \mathrm{~nm}$ diameter pores. The peculiar boundary conditions due to the lateral and confined oxidation conditions probably modify the anticipated equilibrium for the pore organization. For this study, we did not calculate the porosity, since the interpore distance varied between the pores. This is probably due to the boundary situation, as just quoted, and also to the limited anodization time. Actually, according to the general theory of pore formation in PAA structures, pores originate at random positions at the beginning of the anodization. And here, the anodization time is less than $5 \mathrm{~min}$.

For a better observation and to check the ordering across the length of the membrane, we locally etched some of the membranes using a FIB gun. The schematic of the experiment is shown in figures 6(a) and (b). The sample is sputter-etched by the $\mathrm{Ga}$ ions at different places along the length of the membrane and the result is observed using the in situ SEM. The substrates are also etched partially to get the proper window for comfortable observation. During this sputter-etch of the subsequent layers (including the substrate as mentioned) we noticed some re-deposition of the sputtered materials. This is shown in figure 6, where only the central part of the picture reveals the pore structure. For the particular membrane

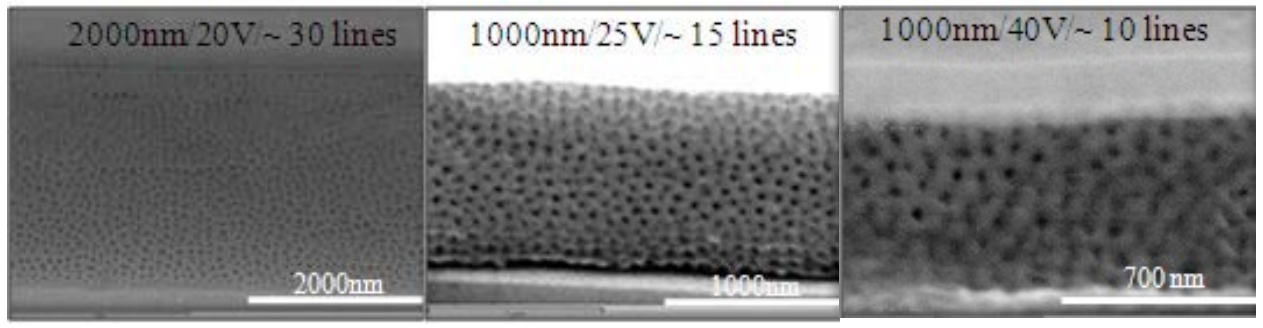

(g)

(h)

(i)

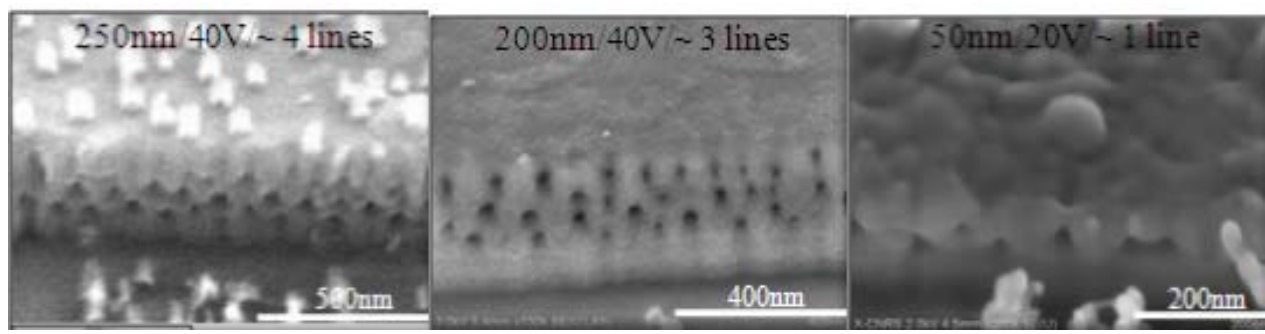

(j)

(k)

(1)

Figure 5. Scanning electron microscope images for the lateral templates with different pore row numbers obtained by changing the thickness of the $\mathrm{Al} \mathrm{film}$ and adapting the anodization voltage (the top of each image indicates the thickness/anodization voltage/number of pore rows). 


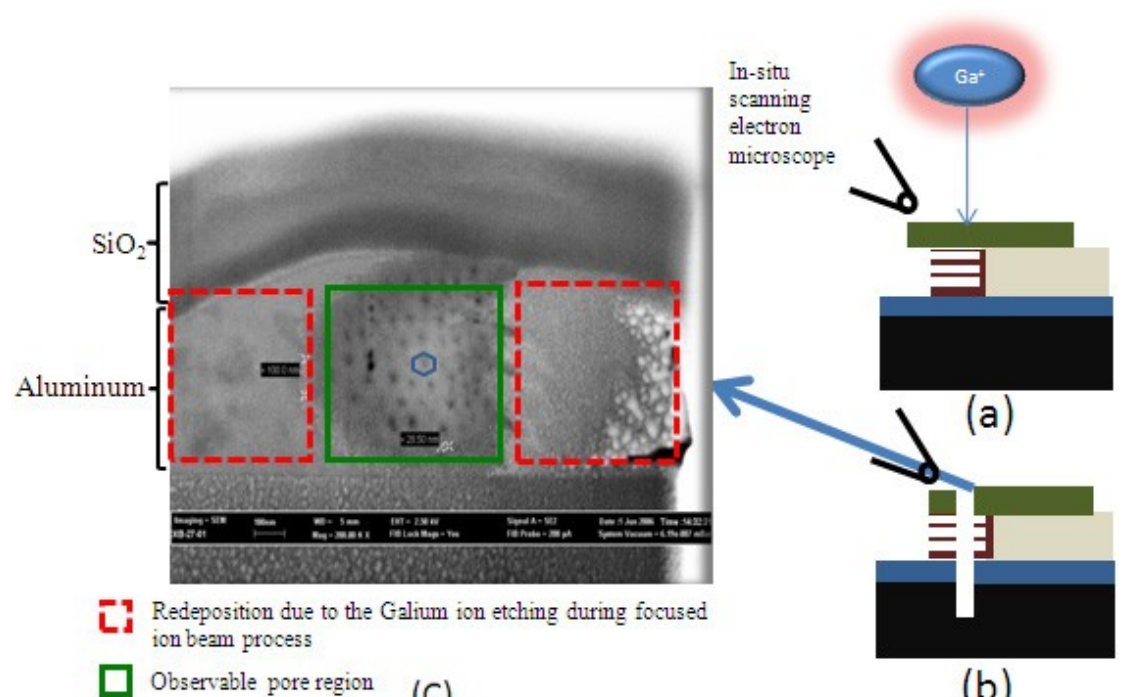

Figure 6. Schematic of the focused ion beam experiment. (a) shows the Ga ions etching the membrane and the in situ SEM. (b) Schematic side view of a membrane after the ion beam etching. Note that the substrate is also etched to some extent in order to get the proper window for view. (c) In situ SEM image of a membrane after the focused ion beam etching; the well-organized pore region is seen clearly in the center part of the picture, whereas re-deposition of ion-sputtered materials blurs the observation on either side.

shown here (oxalic acid $25 \mathrm{~V}$ ), the observed order inside the membrane is comparable to that observed at the edge.

\section{Conclusion}

We showed that the in-plane orientation and position of the nanopores can be lithographically controlled using CMOS compatible techniques. In addition, it should be noted that the present concept can be scaled-up for high integration by using multiple conductive pathways through the silicon wafer. We also showed the possibilities of fabricating one-dimensional array of alumina nanopores down to about $20 \mathrm{~nm}$ in diameter and we observed that the mechanism of pore generation and formation in lateral configuration is almost similar to that of the vertical configuration. Finally, we would like to emphasize that the in-plane alignment of the pores shown in the present work could be advantageous for nanomechanical systems (NEMS) and microfluidics (or rather nanofluidics).

\section{Acknowledgments}

The authors thank C Collet from Thales Research \& Technology for his assistance in focused ion beam experiments. This study was partially supported by the EU project CANDICE (514005-2) as well as by the Samsung Electronics 'NanodiX' Chair.

\section{References}

[1] Tonucci J, Justus B L, Campillo A J and Ford C E 1992 Science 258783
[2] Whitney T W, Jiang J S, Searson P C and Chien C L 1993 Science 2611316

[3] Keller F, Hunter M S and Robinson D L 1953 J. Electrochem. Soc. 100411

[4] O'Sullivan J P and Wood G C 1970 Proc. R. Soc. A 317511

[5] Masuda H and Fukuda K 1995 Science 2681466

[6] Li J, Papadopoulos C, Xu J M and Moskovits M 1999 Appl. Phys. Lett. 75367

[7] Jeong S H, Lee O J and Lee K H 2002 Chem. Mater. 141859

[8] Maschmann M R, Franklin A D, Amama P B, Zakharov D N, Stach E A, Sands T D and Fisher T S 2006 Nanotechnology 173925

[9] Lew K K, Reuther C, Carim A H and Redwing J M 2002 J. Vac. Sci. Technol. B 20389

[10] Masuda H, Nishio K and Baba N 1993 Appl. Phys. Lett. 633155

[11] Cojocaru C S, Padovani J M, Wade T, Mandoli C, Jaskierowicz G, Wegrowe J E, Morral A F and Pribat D 2005 Nano Lett. 4675

[12] Zhang H G, Chen Z, Li T and Saito K 2005 J. Nanosci. Nanotechnol. 51745

[13] Pribat D and Cojocaru C S 2006 Nucl. Instrum. Methods Phys. Res. A 56382

[14] Pribat D, Cojocaru C S, Gowtham M, Eude L, Bondavalli P and Legagneux P 2007 J. Soc. Inf. Disp. 15595

[15] Pribat D, Cojocaru C S, Padovani J M, Wade T, Mandoli C, Jaskierowicz G, Morral A F and Wegrove J E 2005 Proc. SPIE Quantum Sensing and Nanophotonic Devices II 573258

[16] Crouse D, Lo Y H, Miller A E and Crouse M 2000 Appl. Phys. Lett. 7649

[17] Li A P, Muller F, Birner A, Nielsch K and Gösele U 1998 J. Appl. Phys. 846023

[18] Nielsch K, Choi J, Schwirn K, Wehrspohn R B and Gösele U 2002 Nano Lett. 2677

[19] Jessensky O, Muller F and Gösele U 1998 Appl. Phys. Lett. 729 